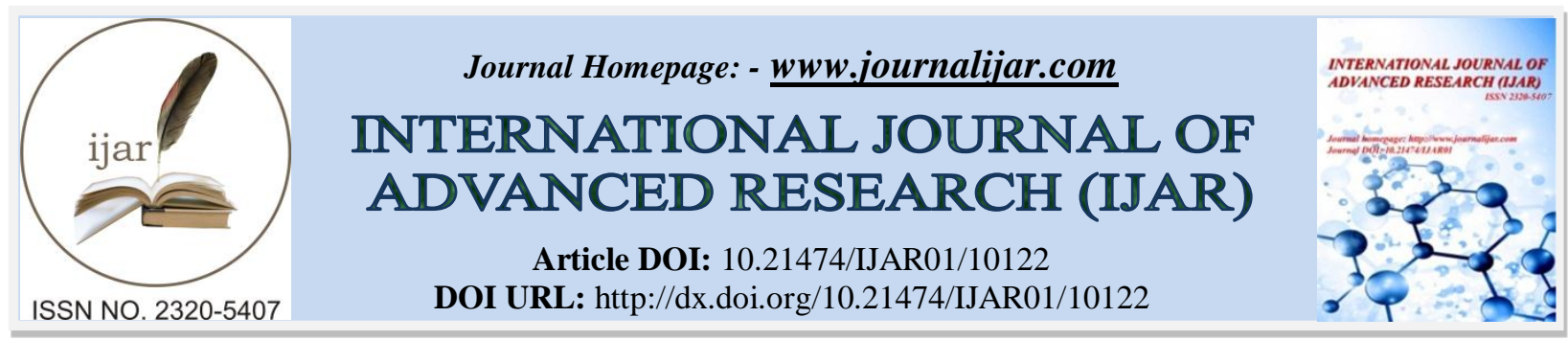

RESEARCH ARTICLE

\title{
URETRAL CANCER IN WOMEN: A CASE REPORT.
}

Souad Maher, Rachida Saouab, Meryem Edderai and Bouchaib Redouane.

Radiology Department, The Military Hospital of Instruction Mohamed V, University, Faculty of Medicine and Pharmacy, Rabat-Morocco.

\section{Manuscript Info}

\section{Manuscript History}

Received: 01 October 2019

Final Accepted: 03 November 2019

Published: December 2019

Key words:

Urethral Meatus Cancer, Woman, Diagnosis, Imaging.

\section{Abstract}

Urethral meateal cancer is a rare condition. The average age of onset is between 50 to 60 years old. This tumor results in a variety of clinical signs, the cytology and histology of the urethral sample are indispensables. Its diagnosis is often late, certainly sometimes unknown. Imaging remains the reference examination to be requested for the extension assessment. The treatment is essentially surgical.

We report the case of a 58-year-old woman with dysuria with general deterioration of the condition for 5 months. The physical examination revealed an edematous, indurated, painful urethral meatus on palpation. Magnetic resonance imaging shows an injury process centered on the urethral meatus without any sign of loco-regional extension.

Urethrocystectomy with colpohysterectomy followed by Bricker-type urinary diversion was performed. Histopathological examination of the part revealed a well-differentiated urethral adenocarcinoma.

Copy Right, IJAR, 2019,. All rights reserved.

\section{Introduction:}

Cancer of the urethra in women is a rare pathology and constitutes $0.02 \%$ of malignant diseases. Patients are usually elderly. The diagnosis of this condition is made difficult by the absence of pathognomonic signs.

Magnetic resonance imaging remains the benchmark examination for better extension assessment. Pathological examination is essential for the diagnosis.

The treatment of this pathology is radio-surgical. The later the diagnosis, the more the surgical procedure is extended to the neighboring organs and the pejorative prognosis.

\section{Material And Methods:}

Mrs. FZ.M, 58 years old, menopausal for 8 years, without pathological antecedents, presents a dysuria in a context of deterioration of the general state evolving since 5 months. The physical examination revealed an edematous, indurated, painful urethral meatus on palpation. The rest of the exam was normal. Cytobacteriological examination of the urine revealed an E. coli urinary tract infection. Magnetic resonance imaging shows poorly limited tissue thickening, located in the anterior urethra, at the level of the muscular region, in discrete T2 hyperintense with gradual moderate enhancement and no sign of locoregional invasion with a bladder fight. Urethrocystectomy with colpohysterectomy followed by Bricker-type urinary diversion was performed. Histopathological examination of the part revealed a well-differentiated urethral adenocarcinoma. The post-operative suites were simple. The patient 
receives a radio-chemotherapy focused on the pelvis completed the treatment. The retreat is 8 months free from any tumor recurrence.

\section{Discussion:-}

Urethral cancer is a rare entity $(1 ; 4 ; 12)$. The incidence of this condition is low, between $0.02 \%$ and $0.05 \%$ of all female cancers $(1 ; 2 ; 7 ; 8)$. Women seem more affected than men $(10 ; 11)$; the predominance of the white race has been reported (10). The average age of onset is between 50 to 60 years, with extremes of 4 to 90 years (9). Several risk factors are known: age, menopause, the presence of precancerous lesions, urethral diverticula, untimely manipulation of the urethra, recurrent infections and chronic or post-traumatic inflammatory stenotic lesions and delivery $3,4,6$.

The diagnosis of this pathology is made difficult by its rarity and the absence of pathognomonic signs. The clinical signs are variable and not very specific, made of urethrorrhagia, dysuria, acute retention of urine, micturition disorders, vulvovaginal disorders and sometimes in the form of vulvar mass. Sometimes urinary leakage is observed, either with urinary incontinence due to infiltration of the urethra and sphincter, or with a type of urinary fistula with a tumoral utero-vaginal fistula.

The key early diagnosis is to think of any dysuria or urine retention in women, in the absence of neurological causes, vesical or uterine.

The most common pathological types are squamous cell carcinoma (80\%) and urothelial tumors (15\%). The other types of adenocarcinomas, melanomas and sarcomas are more anecdotal and account for only 5\% of cases. Urethrography shows specific images such as a marshy gap, rigidity of the urethra or impassable stenosis. The assay of conventional tumor markers would not be of definite utility.

The diagnosis of certainty is based on anatomopathological examination of biopsies taken during urethroscopy or transvaginal. Ultrasound and intravenous urography make it possible to assess possible bladder and ureteral involvement. Pelvic magnetic resonance imaging is the gold standard for assessing local extension, with the tumor appearing as T1 hypointense and T2 hypersignal (Figure 1,2).

The extension of the tumor is mainly local: towards the vulva and the skin in case of distal tumor; to the vagina and bladder if there is a proximal tumor (5). Ganglionic extension is rare at the early stage. Metastases occur mainly in the lungs, liver, brain and bones (6).

The treatment is essentially surgical. For localized tumors of the urethra discovered early, it consists of an endoscopic excision of tumor lesions, otherwise a partial urethral resection can be performed. For distal tumors of the superficial or minimally invasive anterior urethra, treatment is based on radiotherapy (interstitial or combination of interstitial and external radiotherapy), open-air resection, electrocoagulation-fulguration or laser.

Larger and more deeply invasive anterior tumors and proximal urethral tumors require polytherapy with excision surgery and urinary diversion, usually associated with radiotherapy. The surgery involves bilateral, pelvic and sometimes inguinal lymph node dissection, often with removal of part of the pubic symphysis and lower pubic branches. The effectiveness of chemotherapy, which is sometimes used, has not been established.

The longer it takes to diagnose, the more extensive the surgical resection to the surrounding organs is, and the pejorative become the prognosis.

The prognosis depends on the precise topography in the urethra and the extension of the tumor, particularly its depth extension. Survival at 5 years is $>60 \%$ for distal tumors and $10-20 \%$ for proximal tumors. The recidivism rate is > $50 \%$.

\section{Conclusion:-}

Urethral cancer is rare and usually occurs after 50 years. It can occur in both men and women and is the only cancer of the urinary tract that is more common in women. His prognosis is dark. It is to be found in any postmenopausal 
woman with micturition disorders whose etiology is not obvious. Magnetic resonance imaging seems to give good results for the local extension assessment.

\section{Conflicts Of Interest:}

The authors do not declare any conflict of interest.

\section{Contributions From The Authors:}

All authors contributed to this work. All authors have read and approved the final version of the manuscript.

\section{Legend:}
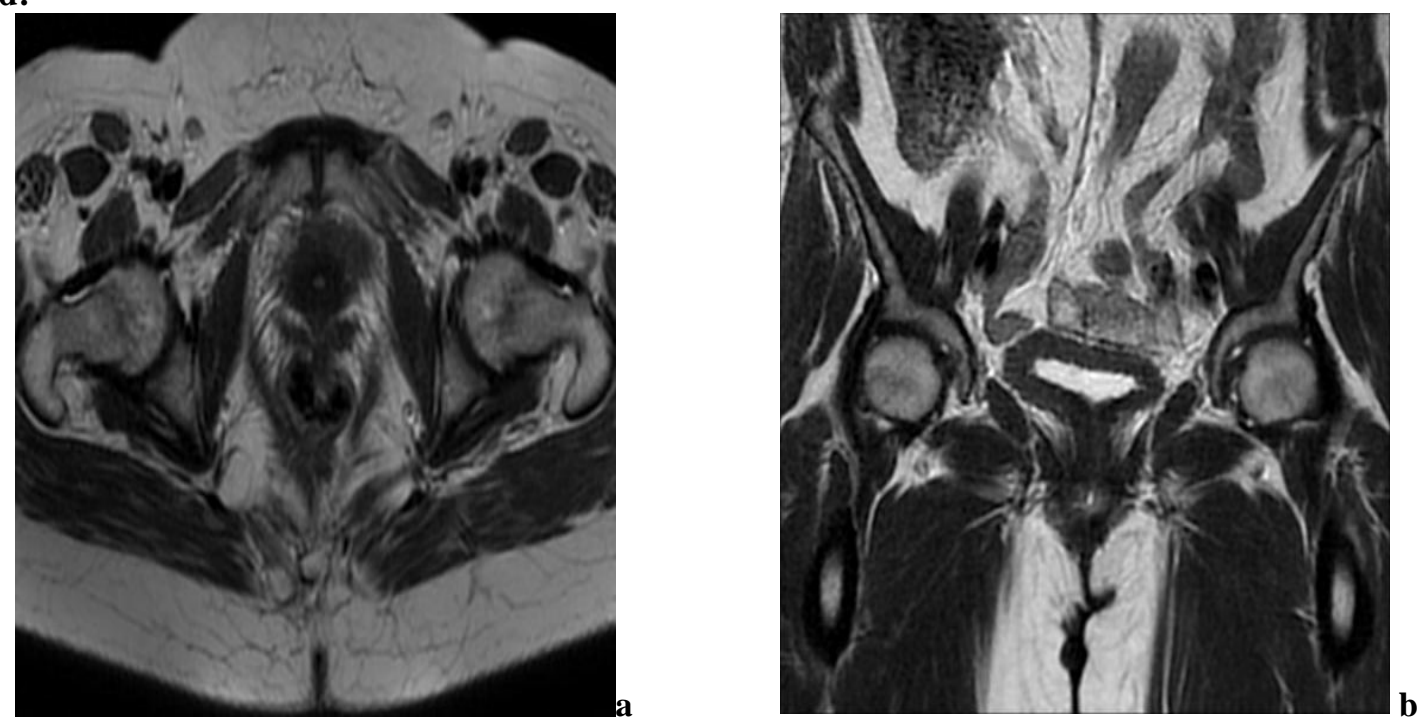

Fig. 1: Pelvic MRI in axial (a) and coronal (b) cuts. T2 without injection sections: shows poorly limited tissue thickening, in T2 hypersignal, at the level of the meatal area of the anterior urethra without signs of locomotor invasion -regional.
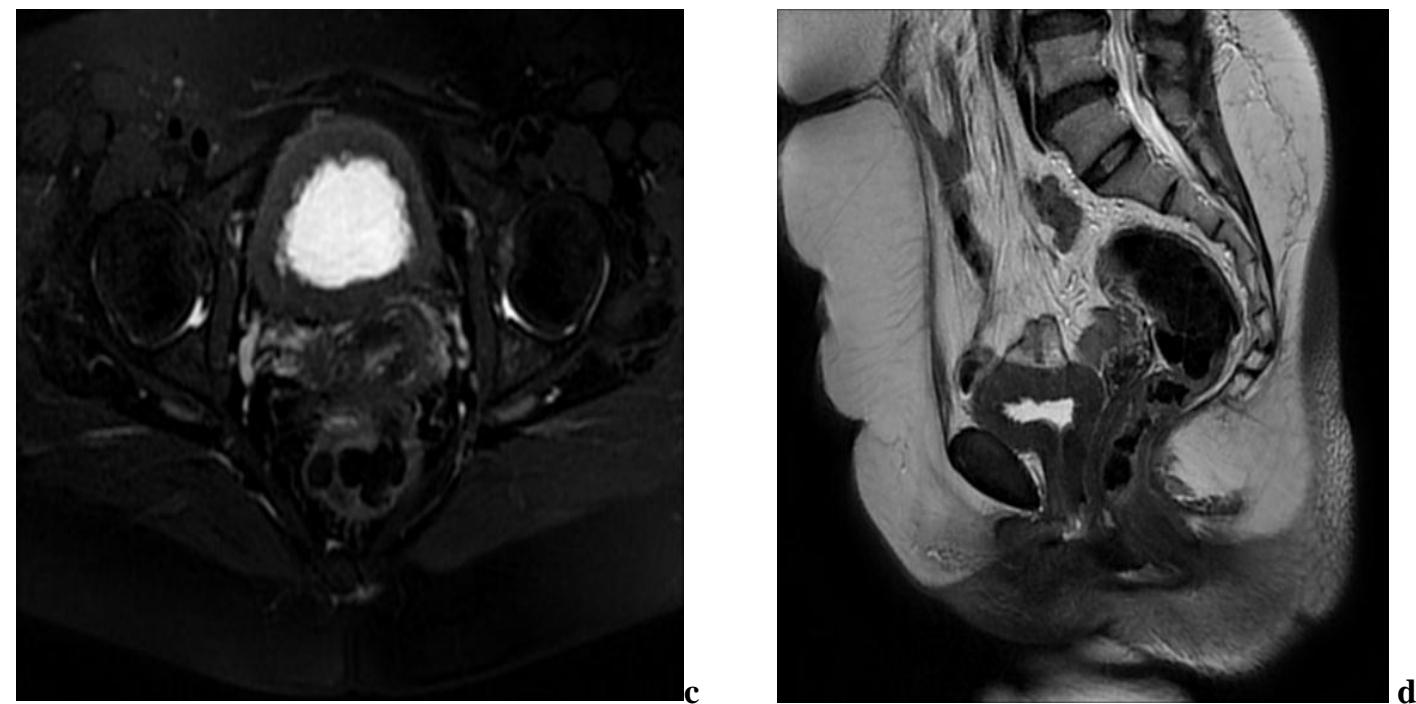

Fig. 2. Pelvic MRI axial (c) and sagittal (d) sections in $\mathrm{T} 2$ sequence after contrast injection: showing moderate tissue enhancement of the anterior urethral meatus. This thickening comes into contact with the bulbo-muscular and pubo rectal muscle with separating margin. It is associated with regular and circumferential vesical wall thickening. 


\section{References:-}

1. AUVERT J.: Tumeurs de l'urètre. In: Cancers Urologiques de l'adulte. Expansion Scientifique Française Milan France, 1989; 337-349.

2. GOMEZ DiAZ M.E., CASTANO D., GONZAleZ-COTO D. C., CAlvo J., C., FERnANDeZ V., M.: Cancer de uretra femenino. Aportacion de un nuevo caso y revision de la literatura. Arch. Esp. Urol., 2002; 55: 568-571

3. Wang X, Bai P, Su H et al. Management of primary adenocarcinoma of the female urethra : report of two cases and review of the literature. Oncol Lett $2012 ; 4(5): 951-4$.

4. Weng WC, Wang CC, $\mathrm{Ho} \mathrm{CH}$ et al. Clear cell carcinoma of female urethral diverticulum-a case report. J Formos Med Assoc $2013 ; 112(8): 489-91$.

5. Gourtsoyianni S, Hudolin T, Sala E et al. MRI at the completion of chemoradiotherapy can accurately evaluate the extent of disease in women with advanced urethral carcinoma undergoing anterior pelvic exenteration. Clin Radiol $2011 ; 66(11): 1072-8$.

6. Karnes RJ, Breau RH, Lightner DJ. Surgery for urethral cancer. Urol Clin North Am 2010 ;37(3) :445-57.

7. MURPHY D.P., PANTUCK A.J., AMENTA P.S., DAS K. M., CUMMINGS K.B., KEENEY G.L., WEISS R.E. Female urethral adenocarcinoma: Immunohistochemical evidence of more than one tissue of origin. J. Urol., 1999; 161:1881

8. WATANABE J., YAMAMOTO S., SOUMA T., HIDA S., TAKASU K.: Primary malignant melanoma of the male urethra. Int. J. Urol., 2000; 7: 351-353.

9. MAHENDRA V., MEMON S.H., DRURRANT D.C.S., DAHAR N., TURNER D.T.L.: Primary urethral transitional cell carcinoma in a female. Br. J. Urol. Inte., 2001; 87: 710-711

10. TAZI K., KARMOUNI T., KOUTANI A., ATTYA A. I., HACHIMI M., LAKRISSA A: Cancer de l'urèthre féminin. A propos de deux nouvelles observations. Prog. Urol., 2000;10:1217-1219

11. TAZI K., MOUDOUNI S., KARMOUNI T., KOUTANI A., HACHIMI M., LAKRISSA A.: Carcinome épidermoide de l'urèthre masculin. Prog. Urol., 2000; 10: 600-602.

12. WATANABE J., YAMAMOTO S., SOUMA T., HIDA S., TAKASU K.: Primary malignant melanoma of the male urethra. Int. J. Urol., 2000; 7: 351-353. 